\title{
SURVEI KEBERSIHAN PERSONAL DENGAN KEBERADAAN TELUR Trichuris trichiura PADA KUKU PETUGAS KEBERSIHAN DI KRIAN, SIDOARJO
}

\author{
Survey on Personal Hygiene Toward Trichuris trichiura's Egg to a Nail's Janitors at \\ Krian, Sidoarjo \\ ${ }^{1}$ Acivrida Mega Charisma, ${ }^{2}$ Bunga Vicencia Dewantari, ${ }^{3}$ Farida Anwari \\ ${ }^{1,2,3}$ STIKES RS Anwar Medika
}

Koresponden : acie.vrida@gmail.com/085855778561

\begin{abstract}
There are 795 million sufferers of Trichiuris trichiura infection. One of the transmissions is through dirty fingernails. This study aims to determine the existence of Trichiuris trichiura worm eggs and the relationship of personal hygiene to environmental cleaner troops in Krian area, Sidoarjo Regency. This research method using cross sectional design with 25 respondents. Examination of nail samples using the $\mathrm{NaCl}$ and eosin methods. Then the statistical analysis was tested using fisher exact. The results showed that 2 respondents (8\%) of 25 respondents found Trichiuris trichiura worm eggs using random sampling. The results of the analysis of all categories showed that there was no significant relationship to the presence of Trichiuris trichiura worm eggs with the significance of the habit of washing hands with soap before eating $p$-value $=0.480$; habit of washing hands with soap after defecating $p$-value $=0.520$; habit of cutting nails once a week $p$-value $=0.070$; and habit of taking deworming medicine every six months $p$ value $=1,000$. The conclusion of this study, there is no significant relationship between personal hygiene and the presence of TT worm eggs, but there are several categories of personal hygiene that are lacking in environmental cleaner troops based on the results of cross tabulation so that worm eggs were found in this study.
\end{abstract}

Keywords : Janitors, Nail, Personal hygiene, Trichiuris trichiura

\begin{abstract}
ABSTRAK
Penderita infeksi Trichiuris trichiura tercatat 795 juta orang. Salah satu penularannya melalui perantara kuku tangan yang kotor. Penelitian ini bertujuan untuk mengetahui keberadaan telur cacing Trichiuris trichiura dan hubungan kebersihan personal pada petugas kebersihan lingkungan di daerah Krian, Kabupaten Sidoarjo. Metode penelitian ini menggunakan desain cross sectional sebanyak 25 responden. Pemeriksaan sampel kuku menggunakan metode $\mathrm{NaCl}$ dan eosin. Kemudian di uji analisa secara statistik menggunakan fisher exact. Hasil penelitian menunjukkan ditemukan adanya telur cacing Trichiuris trichiura sebanyak 2 responden (8\%) dari 25 responden menggunakan random sampling. Hasil analisis seluruh kategori menunjukkan tidak terdapat hubungan yang signifikan terhadap keberadaan telur cacing Trichiuris trichiura dengan hasil signifikansi kebiasaan cuci tangan dengan sabun sebelum makan $p$-value $=0,480$; kebiasaan cuci tangan dengan sabun setelah $\mathrm{BAB} p$-value $=0,520$; kebiasaan memotong kuku seminggu sekali $p$-value $=0,070$; dan kebiasaan minum obat cacing tiap enam bulan sekali $p$-value $=1,000$. Kesimpulan penelitian ini yaitu tidak terdapat hubungan kebersihan personal
\end{abstract}


dengan keberadaan telur cacing TT yang signifikan namun ada beberapa kategori kebersihan personal yang kurang pada petugas kebersihan lingkungan berdasarkan hasil tabulasi silang sehingga telur cacing ditemukan pada penelitian ini.

Kata kunci: Kebersihan personal, Kuku, Petugas kebersihan, Trichiuris trichiura

\section{PENDAHULUAN}

Menurut WHO (2012) sebanyak dua miliyar orang terinfeksi cacing diantaranya 300 juta menderita infeksi kecacingan berat dan 150.000 orang meninggal akibat infeksi STH (Soil Transmitted Helminth). Soil Transmitted Helminths (STH) merupakan Infeksi helminthiasis yang disebabkan oleh golongan nematoda usus. Salah satunya Trichiuris trichiura dan dilaporkan sebanyak 795 juta terkena trichiuriasis. Beberapa faktor yang dapat menyebabkan terinfeksi antara lain kurangnya kebersihan pribadi, sanitasi, tingkat pengetahuan, tingkat sosial dan ekonomi. Adapun cara penularannya melalui perantara vektor, kontak langsung seperti kuku, dan menelan telurnya (Resnhaleksmana 2014). Kuku yang terkontaminasi mengandung telur akan masuk mulut yang kemudian masuk di dalam usus menjadi larva dan dewasa (Zulkoni, 2011).

Menurut Brooker dan Bundy, (2014) Infeksi ini terjadi secara langsung dan sering ditemukan di daerah tropis dengan curah hujan yang tinggi, temperatur yang hangat, dan sanitasi yang buruk. Apabila terinfeksi maka penderita dapat mengalami 2 kategori diantaranya kategori infeksi ringan yang bersifat asimtomatis dan kategori infeksi berat akan menimbulkan gejala pencernaan, anemia, dan gangguan kognitif. Seperti pada penelitian (Amran 2017), menyebutkan bahwa infeksi kecacingan berhubungan dengan kejadian penyakit anemia di Kota Makasar sebanyak 35\%.

Oleh karena itu, pada penelitian ini akan mensurvei kebersihan personal dan pemeriksaan keberadaan telur cacing Trichiuris trichiura pada kotoran kuku petugas kebersihan di Krian, kabupaten Sidoarjo karena berdasarkan penelitian (Souisa 2019) sampel kuku merupakan sampel yang mudah dikumpulkan dan cara penularannya melalui fecal oral. Sehingga tujuan untuk mengetahui keberadaan telur cacing TT pada petugas kebersihan dan hubungan kebersihan personal dengan keberadaan telur cacing Trichiuris trichiura dapat teridentifikasi.

\section{METODE}

\section{Desain, tempat dan waktu}

Desain penelitian ini yaitu cross sectional dengan pemeriksaan sampel kuku petugas kebersihan lingkungan daerah Krian, Sidoarjo di Laboratorium Biologi RS Anwar Medika dan pembagian kuesioner untuk menganalisis hubungan kebersihan personal dari bulan Maret- Juni 2020.

\section{Jumlah dan cara pengambilan subjek}

Populasi subjek penelitian ini adalah petugas kebersihan di daerah Krian, Sidoarjo dimana cara pengambilan subjek dilakukan secara random sampling dengan 25 subjek penelitian dengan menggunakan rumus Slovin. Perhitungannya adalah:

$$
\mathrm{n}=\mathrm{N} /\left(1+\left(\mathrm{Nx} \mathrm{e}^{2}\right)\right)
$$

Keterangan:

n : Ukuran Sampel

N : Ukuran Populasi

e : Persen kelonggaran ketidaktelitian karena kesalahan pengambilan sampel yang masih dapat ditoleransi atau 
diinginkan misalnya $2 \%$.

Sehingga: $\mathrm{n}=25 /\left(1+\left(25 \times 0,04^{2}\right)\right)$

$\mathrm{n}=25 /(1+(25 \times 0,0004))$

$\mathrm{n}=25 /(1+0,01)$

$\mathrm{n}=25 / 1,01$

$\mathrm{n}=25$ sampel

\section{Bahan dan alat}

Bahan yang digunakan meliputi $\mathrm{NaCl}$ 0,09\% untuk merendam sampel, Etanol 95\% untuk membersihkan kaca objek, Eosin 2\% untuk pewarnaan sampel feses, alcohol swab, handscoon, dan masker sedangkan alat yang digunakan meliputi mikroskop binokuler, kaca objek, spatula, kaca penutup, tabung reaksi, rak tabung reaksi, sentrifuse, dan pot sampel. Metode yang digunakan adalah pemeriksaan langsung.

\section{Jenis dan Cara Pengumpulan Data}

Pengumpulan data primer subjek dilakukan berdasarkan kriteria inklusi dan eksklusi dimana kriteria inklusi meliputi petugas kebersihan lingkungan yang tidak memakai alat pelindung diri (APD), bersedia mengumpulkan sampel kuku, dan mengisi kuesioner terkait dengan kebersihan personal. Sedangkan kriteria eksklusi meliputi tidak bersedia menjadi responden dalam penelitian ini.

\section{Langkah-Langkah Penelitian}

Sampel potongan kuku yang telah diperoleh dalam wadah yang bersih dan kering tanpa pengawet. Wadah yang paling cocok adalah wadah yang bertutup rapat (pot sampel). Hal-hal yang harus diperhatikan yaitu sampel kuku jangan sampai terpapar udara dalam wadah tanpa penutup dan tidak boleh tercampur dengan sampel yang lain. Sampel kuku harus di periksa dalam 1-4 jam setelah pengambilan. Pengambilan sampel kuku ini kami lakukan pada petugas kebersihan lingkungan daerah Krian Kabupaten Sidoarjo setelah bekerja.

Sampel kuku yang diperoleh di rendam dengan nacl $0.09 \%$ selama 20 menit. Kemudian di sentrifuse kecepatan $2500 \mathrm{rpm}$ dan saring dengan kasa. Kaca objek yang telah dibersihkan dengan etanol $95 \%$ diteteskan sedimen sampel dan eosin $2 \%$ sebanyak 1-2 tetes, lalu diratakan sampai membentuk lingkaran dan tutup dengan kaca penutup. Setelah itu dilakukan pengamatan pada mikroskop dengan pembesaran 100x.

\section{Pengolahan dan analisis data}

Data yang diperoleh di kumpulkan dan di analisis dengan crosstabs dan SPSS menggunakan uji fisher exact yang di sajikan dalam bentuk tabel.

\section{HASIL}

Hasil karakteristik responden tabel 1 menunjukkan sebanyak 25 responden yang berjenis kelamin perempuan sebanyak 1 responden (4\%) dan berjenis kelamin laki-laki sebanyak 24 responden (96\%). Responden yang berusia 21-30 tahun sebanyak 4 responden (16\%), usia 31-40 tahun sebanyak 10 responden (40\%), usia 4150 tahun sebanyak 8 responden $(32 \%)$, dan usia 51-60 tahun sebanyak 3 responden (12\%). Sedangkan responden yang pendidikan terakhir SD sebanyak 13 responden (52\%), responden yang berpendidikan terakhir SMP sebanyak 10 responden (40\%), dan responden yang berpendidikan terakhir SMA sebanyak 2 responden (8\%).

Pada hasil pemeriksaan tabel 3 menunjukkan sebanyak 25 responden terdapat 2 responden $(8 \%)$ positif terdapat telur cacing TT dengan ciri-ciri berbentuk seperti tong anggur dengan penonjolan jernih pada kedua kutub yang diketahui sebagai mucoid plugs. Bagian luarnya berwarna kekuning-kuningan dan bagian dalamnya jernih, berisi massa yang tidak bersegmen. Sedangkan 23 responden $(92 \%)$ negatif telur cacing TT. 
Hasil kuesioner kebersihan personal tabel 2 menunjukkan dari 25 responden yang memiliki kebiasaan cuci tangan dengan sabun sebelum makan sebanyak 12 responden (48\%), kebiasaan cuci tangan dengan sabun setelah BAB sebanyak 9 responden (36\%), kebiasaan memotong kuku seminggu sekali sebanyak 18 responden (72\%), kebiasaan minum obat cacing tiap enam bulan sekali hanya 1 responden $(4 \%)$, yang tidak memiliki kebiasan cuci tangan dengan sabun sebanyak 13 responden (52\%), yang tidak memiliki kebiasaan cuci tangan dengan sabun setelah BAB sebanyak 16 responden $(64 \%)$, yang tidak memiliki kebiasaan memotong kuku seminggu sekali sebanyak 7 responden (28\%), dan yang tidak memiliki kebiasaan minum obat cacing tiap enam bulan sekali sebanyak 24 responden (96\%).

Hasil analisis secara statistika tabel 4 dari seluruh kategori menunjukkan tidak terdapat hubungan yang signifikan terhadap keberadaan telur cacing Trichiuris trichiura dengan hasil signifikansi kebiasaan cuci tangan dengan sabun sebelum makan $p$-value $=$ 0,480 ; kebiasaan cuci tangan dengan sabun setelah $\mathrm{BAB} p$-value $=0,520$; kebiasaan memotong kuku seminggu sekali $p$-value $=0,070$; dan kebiasaan minum obat cacing tiap enam bulan sekali $p$-value $=1,000$.

\section{PEMBAHASAN}

Berdasarkan hasil analisis secara statistik tabel 4, semua kategori kebersihan personal menunjukkan tidak terdapat hubungan yang signifikan dengan keberadaan telur cacing TT. Hal ini dikarenakan kebersihan personal yang kurang baik lebih besar dibanding kebersihan personal yang baik sehingga tidak sebanding dengan jumlah keberadaan telur cacing TT.

Hal ini sejalan dari beberapa penelitian diantaranya penelitian (Mulan Tirtayanti, Dewi Widhya 2016) menyebutkan bahwa responden yang tidak mencuci tangan, tidak memotong kuku, dan tidak memakai perlindungan tangan ternyata tidak ditemukan adanya telur cacing TT pada sampel kuku petugas pengrajin genteng tanah liat di desa Pejanten, Kediri, Tabanan; Penelitian (Herdiansyah and Santoso 2019) menyebutkan bahwa tidak ada hubungan kebersihan diri dengan keberadaan telur cacing sampel kuku pada nelayan Cijulang Pangandaran dan penelitian (Nundrisari 2019) juga melaporkan bahwa tidak ada hubungan yang signifikan hygiene perorangan dengan kejadian infeksi STH terutama Trichiuriasis pada petugas perkebunan Garahan Kidul.

Selain itu, peneliti berasumsi bahwa keberadaan jumlah telur cacing TT tidak sebanding dengan tingginya kebersihan personal yang kurang baik disebabkan oleh kurangnya kotoran kuku yang berpotensial terhadap keberadaan telur cacing TT karena petugas kebersihan tidak hanya berkontak dengan media tanah yang lembab saat bekerja, melainkan mereka juga berkontak dengan media lingkungan lainnya. Mengingat telur cacing TT memiliki siklus hidup yang cukup lama dan berada di media tanah yang lembab (Mulan Tirtayanti, Dewi Widhya 2016) Berbeda dengan kelompok anak-anak yang selalu berkontak dengan tanah karena mereka suka dan memiliki kebiasaan bermain di tanah sehingga lebih mudah ditemukan keberadaan telur cacing TT (Putri, Lesmana, and Restuastuti 2017)

Dengan demikian, meskipun hasil statistika tidak terdapat hubungan yang signifikan namun berdasarkan analisis tabulasi silang (tabel 4) terdapat tiga kategori kebersihan personal yang kurang baik menjadi penyebab adanya 
telur cacing TT yang ditularkan diantaranya tidak mencuci tangan dengan sabun sebelum makan, tidak mencuci tangan dengan sabun setelah $\mathrm{BAB}$, dan tidak minum obat cacing selama enam bulan sekali. Pemberian obat cacing Albendazol $400 \mathrm{mg}$ dosis tinggal saat efektif terutama terhadap infeksi Trichiuris trichiura (Charisma, dkk, 2020)

\section{KESIMPULAN}

Kesimpulan dari penelitian ini yaitu ditemukan keberadaan telur cacing TT sebanyak 2 subjek penelitian $(8 \%)$ pada petugas kebersihan lingkungan. Hasil analisis secara statistik menunjukkan tidak terdapat hubungan yang signifikan antara kebersihan personal dengan keberadaan telur cacing TT, namun ada beberapa kebersihan personal yang kurang pada petugas kebersihan lingkungan sehingga telur cacing tetap ditemukan.

\section{SARAN}

Saran untuk penelitian ini yaitu perlunya dilakukan promosi kesehatan secara rutin oleh dinas kesehatan maupun dinas kebersihan kabupaten mengenai kebersihan personal, sebaiknya petugas kebersihan juga lebih memperhatikan terkait kebersihan personal guna mencegah terkontaminasi telur cacing masuk ke mulut, dan perlu dilakukan penelitian lanjutan mengenai pemeriksaan kuku terhadap keberadaan telur cacing STH yang lain seperti hookworm, dan pemeriksaan pada sampel feses terkait keberadaan telur cacing Trichiuris trichiura.

\section{UCAPAN TERIMA KASIH}

Peneliti mengucapkan terimakasih kepada STIKES RS Anwar Medika, petugas kebersihan lingkungan daerah Krian kabupaten Sidoarjo yang telah berpartisipasi, dan pihak-pihak terkait yang telah membantu serta mendukung dalam penelitian ini.

\section{DAFTAR PUSTAKA}

Amran, Prawansa. 2017. "Prevalensi Penyakit Kecacingan Dan Hubungannya Dengan Anemia Pada Anak Sekolah Dasar Yang Ada Di Kota Makassar." Jurnal Media Analis Kesehatan 8(2):5966.

Brooker, S. J., dan D. A. P. Bundy. 2014. Soil-Transmitted Helminth (Geohelminth). Manson's Tropical Infectious Disease, 23: 766-794.

Charisma, A. M., Farida, E. A., Wahyuni, K. I., \& Dewi, Y. E. N. K. 2020. Prevalensi Telur Cacing Nematoda Usus Soil Transmited Helmint (Sth) Dengan Metode Konsentrasi Pada Siswa Mi Sunan Ampel 1 SidorogoTrosobo Kecamatan Taman Kabupaten Sidoarjo Provinsi Jawa Timur. Journal of Pharmaceutical Care Anwar Medika (J-PhAM), 2(2), 1-12.

Herdiansyah, Dadang and Slamet Sudi Santoso. $2019 . \quad$ "Analisis Kebersihan Diri Terhadap Keberadaan Telur Cacing Ascaris Pada Kuku Nelayan Desa Batu

Karas Cijulang Pangandaran.” Jurnal Kedokteran Dan Kesehatan 15(1):94.

Mulan Tirtayanti, Dewi Widhya, Sri Dhyanaputri. 2016. "Identifikasi Telur Cacing Nematoda Usus Pada Kuku Tangan Pengrajin Genteng Di Desa Pejaten, Kediri." Meditory: The Journal of Medical Laboratory 4(2):109-17.

Nundrisari, Dharatri. 2019. "Hubungan Antara Sanitasi Lingkungan Dan Higiene Perorangan Dengan Kejadian Infeksi Soil-Transmitted 
Helminthes Pada Pekerja Perkebunan Garahan Kidul."

Putri, Dwi Julianika, Suri Dwi Lesmana, and Tuti Restuastuti. 2017. "Prevalensi Telur Ascaris Lumbricoides Dan Trichuris Trichiura Pada Kotoran Kuku Tangan Murid Kelas I, II, Dan III SD Negeri 013 Meranti Pandak Kecamatan Rumbai Pesisir Pekanbaru Serta Gambaran Faktor Risiko." Jurnal Ilmu Kedokteran 4(2): 108.

Resnhaleksmana, Ersandhi. 2014. "Prevalensi Nematoda Usus Golongan Soil Transmitted Helminthes (STH) Pada Peternak Di Lingkungan Gatep Kelurahan Ampenan Selatan." Media Bina Ilmiah 8(5):45-50.

Souisa, Gracia Victoria. 2019. "Identifikasi Telur Cacing Pada Kuku Dan Personal Higiene Peserta Didik Di Sekolah Dasar." Tunas-
Tunas Riset Kesehatan 9(36):21620.

WHO. 2012. Weekly Epidemiological Record. Geneva, World Health Organization. http://www.who.int/topics/helmi nthiasis/en/ (Diakses tanggal 11 November 2019).

Zulkoni. 2011. Parasitologi untuk Keperawatan, Kesehatan Masyarakat. Yogyakarta: Nuha Medika. 
Tabel 1

Distribusi Frekuensi Karakteristik Responden Petugas Kebersihan Lingkungan Krian,

\begin{tabular}{|c|c|c|}
\hline \multicolumn{3}{|c|}{ Sidoarjo } \\
\hline Karakteristik & $\mathbf{n}$ & $\%$ \\
\hline \multicolumn{3}{|l|}{ Jenis Klamin } \\
\hline Laki-laki & 24 & 96 \\
\hline Perempuan & 1 & 4 \\
\hline Total & 25 & 100 \\
\hline \multicolumn{3}{|l|}{ Umur } \\
\hline 21-30 tahun & 4 & 16 \\
\hline 31-40 tahun & 10 & 40 \\
\hline 41-50 tahun & 8 & 32 \\
\hline 51-60 tahun & 3 & 12 \\
\hline Total & 25 & 100 \\
\hline \multicolumn{3}{|l|}{ Riwayat } \\
\hline Pendidikan & 13 & 52 \\
\hline $\mathrm{SD}$ & 10 & 40 \\
\hline SMP & 2 & 8 \\
\hline \multicolumn{3}{|l|}{ SMA } \\
\hline Total & 25 & 100 \\
\hline
\end{tabular}

Tabel 2

Distribusi Frekuensi Kebersihan Personal Petugas Kebersihan Lingkungan Krian, Sidoarjo

\begin{tabular}{lcc}
\hline \multicolumn{1}{c}{ Kategori Kebersihan Personal } & n & \% \\
\hline 1. Kebiasaan cuci tangan dengan sabun sebelum makan & & \\
Ya & 12 & 48 \\
Tidak & 13 & 52 \\
\hline 2. Kebiasaan cuci tangan dengan sabun setelah BAB & & \\
Ya & 9 & 36 \\
Tidak & 16 & 64 \\
\hline 3.Kebiasaan menggunakan alas kaki saat membersihkan & & \\
sampah & 11 & 44 \\
Ya & 14 & 56 \\
Tidak & & \\
\hline 4. Kebiasaan memotong kuku seminggu sekali & 18 & 72 \\
Ya & 7 & 28 \\
Tidak & & \\
\hline 5. Kebiasaan minum obat cacing 6 bulan sekali & 1 & 4 \\
Ya & 24 & 96 \\
Tidak &
\end{tabular}


Tabel 3

Hasil Pemeriksaan Kotoran Kuku Petugas Kebersihan Lingkungan Krian, Sidoarjo

\begin{tabular}{lcc}
\hline \multirow{2}{*}{ Hasil } & \multicolumn{2}{c}{ Jumlah Keberadaan Telur Cacing } \\
\cline { 2 - 3 } & $\mathbf{N}$ & \% \\
\hline Positif & 2 & 8 \\
\hline Negatif & 23 & 92 \\
\hline
\end{tabular}

Tabel 4

Tabulasi Silang dan Hasil Statistika ( $p$-value) Hubungan Kebersihan Personal dengan Keberadaan Telur Cacing Trichiuris trichiura

\begin{tabular}{|c|c|c|c|}
\hline \multirow{3}{*}{ Kategori } & \multicolumn{2}{|c|}{ Telur Cacing } & \multirow{3}{*}{$p$-value } \\
\hline & Positif & Negatif & \\
\hline & $\mathrm{n}(\%)$ & $\mathrm{n}(\%)$ & \\
\hline \multicolumn{4}{|l|}{$\begin{array}{l}\text { Kebiasaan cuci tangan dengan } \\
\text { sabun sebelum makan }\end{array}$} \\
\hline $\begin{array}{l}\text { sabun sebelum makan } \\
\text { Ya }\end{array}$ & $11(84,6)$ & $2(15,4)$ & 0,480 \\
\hline Tidak & $12(100)$ & $0(0)$ & \\
\hline \multicolumn{4}{|l|}{$\begin{array}{l}\text { Kebiasaan cuci tangan dengan } \\
\text { sabun setelah BAB }\end{array}$} \\
\hline Ya & $14(87,5)$ & $2(12,5)$ & 0,520 \\
\hline Tidak & $9(100)$ & $0(0)$ & \\
\hline $\begin{array}{l}\text { Kebiasaan memotong kuku } \\
\text { seminggu sekali }\end{array}$ & $5(71,4)$ & $2(28,6)$ & 0,070 \\
\hline $\mathrm{Ya}$ & $18(100)$ & $0(0)$ & \\
\hline Tidak & & & \\
\hline \multicolumn{4}{|l|}{$\begin{array}{l}\text { Kebiasaan minum obat cacing } 6 \\
\text { bulan sekali }\end{array}$} \\
\hline $\mathrm{Ya}$ & $22(91,7)$ & $2(8,3)$ & 1,000 \\
\hline Tidak & $1(100)$ & $0(0)$ & \\
\hline
\end{tabular}

Dokumentasi Hasil Petugas Lingkungan Yang Terinfeksi Cacing Trichiuris trichiura

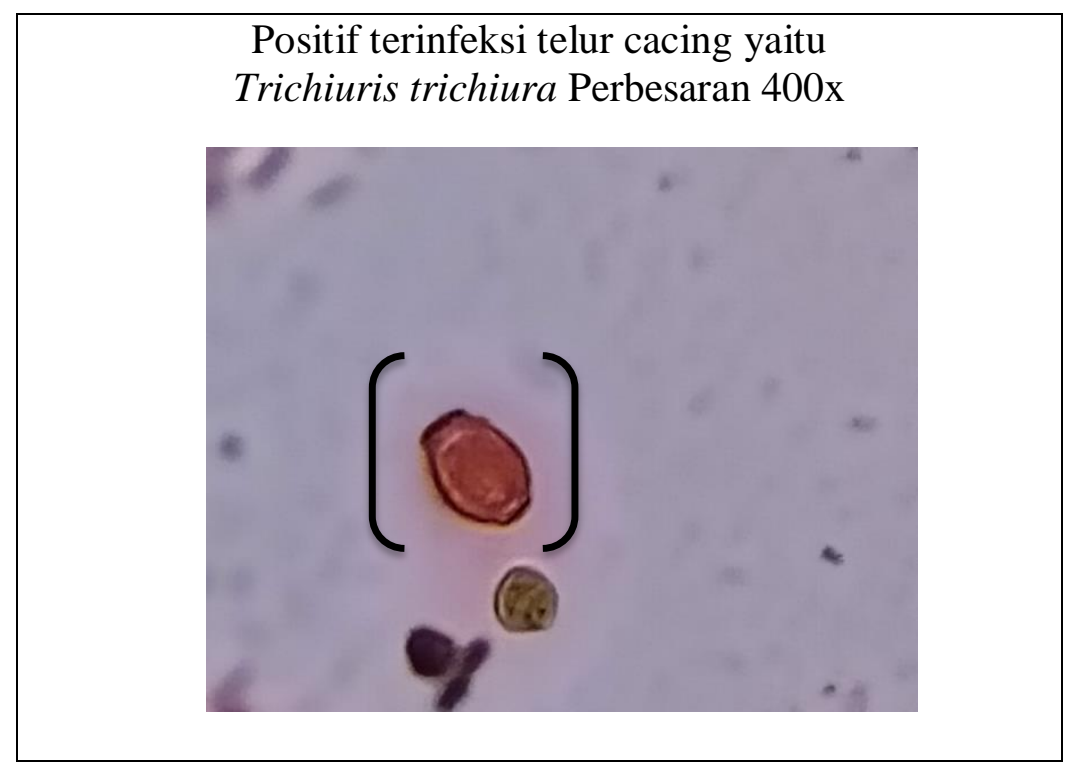

